\section{FOR HYPERSENSITIVITY AND GUM PROBLEMS}

Join GSK to find out more about Sensodyne and Corsodyl on stand H04 at BDTA Dental Showcase.

The stand will feature information about NEW Sensodyne Complete Protection, which is powered by NovaMin technology. Sensodyne Complete Protection offers all-round care for dentine hypersensitivity sufferers, with twice daily brushing.
Also discover why Corsodyl is the number 1 dentist recommended brand for gum problems. Corsodyl treatment mouthwash (chlorhexidine digluconate) treats and prevents gingivitis, with twice daily use.

The GSK team will be available to provide toothpaste samples and discuss products. To request samples visit www. gsk-dentalprofessionals.co.uk.

\title{
SAVE TIME AND MONEY ON STAFF TRAINING
}

For dental practice managers, keeping up to date with staff training is a high priority, for their own assurance and to ensure compliance with

$\mathrm{CQC}$ requirements.

Often there are difficulties in providing cover for staff whilst they are training and high costs associated with the provision of external training sessions.

The Blue Stream Academy Dental Suite has been designed to specifically overcome these pitfalls, which makes it the leader in its field of eLearning and a 'must have' for all practice managers.

This set of modules designed especially for dental practices saves time and money; it also solves the logistical problem of getting all staff members together in one place at the same time to carry out the training. The suite can be accessed anywhere there is an Internet connection; it can be completed at home or on a mobile device.

There are over 20 CPD accredited modules covering all 16 outcomes for CQC compliance which are regularly updated to ensure their relevance and accuracy.

Go to www.bluestreamacademy.com or visit stand L01D at BDTA Dental Showcase.

\section{BREATH CONFIDENCE BACKED BY RESEARCH}

The UltraDEX range delivers fresh breath confidence, whitening maintenance and exceptional oral health, when used as part of a daily oral care regimen. The clinically proven technology is antibacterial, working with the natural oral $\mathrm{pH}$ level and releasing the appropriate amount of active ingredient. UltraDEX eliminates, not simply masks, odourcausing Volatile Sulphur Compounds (VSCs) on contact, lifts organic stains film. Bacteria cannot become resistant and regrowth is inhibited. and breaks down bacterial plaque bio-

Three exciting new products have joined the UltraDEX range: UltraDEX Recalcifying \& Whitening Toothpaste, dual powered by SensiShield and iQ+ Active0xi Technology; UltraDEX WireFree Interdental Brushes coated with iQ+ Active0xi Technology; and UltraDEX Anti-bacterial Coated Interdental Tape, powered by stabilised chlorine dioxide.

UltraDEX personalised Oral Healthcare Kits are also available. .

To obtain samples, book your free UltraDEX webinar training session or find out more, visit stand A05 at BDTA Dental Showcase or go to www.periproducts.co.uk.

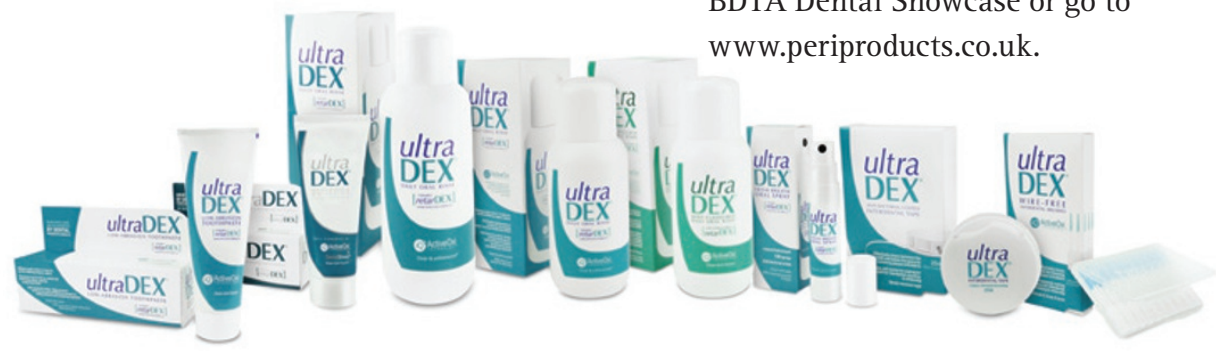

STUDY HIGHLIGHTS

\section{PREVALENCE OF TOOTH WEAR}

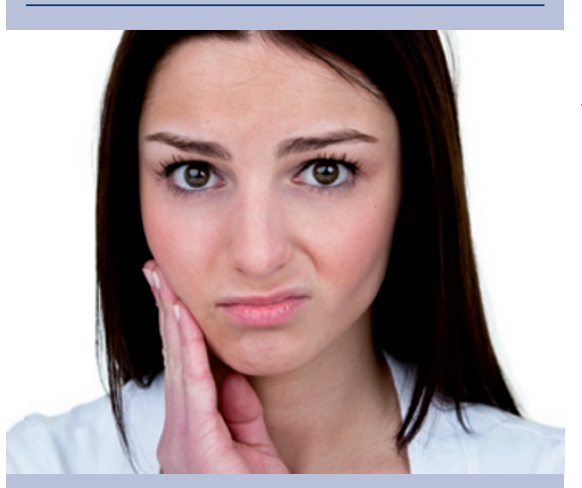

A new study supported by GlaxoSmithKline Consumer Healthcare (GSK) - ESCARCEL - reveals that almost one in three young adults suffer from tooth wear and that dentine hypersensitivity is extremely prevalent in young adults. ${ }^{1}$

The new research identifies a need to regularly screen patients for these conditions.

The ESCARCEL study of 3,187 subjects aged 18-35 across seven European countries is the first pan-European Epidemiology Study on Non-Carious Cervical Lesions (NCCL) and Associated Risk Factors. It looked at tooth wear risk factors and found that those with frequent acidic food intake had higher levels of damage.

The study also clearly identifies that erosive factors (extrinsic and/ or intrinsic acid challenge, such as dietary acids or gastric reflux) strongly associated with tooth wear are also closely associated with dentine hypersensitivity. This fact had not been proven previously due to an absence of studies measuring both conditions simultaneously.

The researchers and GSK say that the study results confirm the essential role of the dental healthcare professional in identifying patients who may be at risk from acid wear and those with dentine hypersensitivity.

1. Bourgeois D et al. Is dental erosion and dentin hypersensitivity a public health problem?: Rationale of the European Collaborative Study. Presented at 101st FDI Annual World Dental Congress, 28-31 August 2013, Istanbul, Turkey. 